\title{
Complete molar pregnancy in a 53-year-old woman
}

\section{Narosha Adroos MB ChB \\ Department of Diagnostic Radiology Pretoria Academic Hospital}

\section{Introduction}

This case emphasises the role of sonography in the diagnosis of a complete molar pregnancy.

\section{Case report}

A 53-year-old female, para 13 gravid 13, presented to the casualty department of Pretoria Academic Hospital with a complaint of PV (per vagina) bleeding.

On clinical examination she was found to be anaemic and had an enlarged, $20 \mathrm{~cm}$ uterus, with adnexal tenderness.

Routine blood tests were normal, except for a B-HCG level of 843636 IU/l. On transabdominal sonar the uterus measured approximately 23 $\mathrm{cm}$ in length $\mathrm{x} 12 \mathrm{~cm}$ in width with hyperechoic vesicular contents and densely packed multiple small cysts. No fetus was found. The rest of the abdomen and pelvis were normal. A diagnosis of complete molar pregnancy was made (Figs la and b).

The patient underwent a total

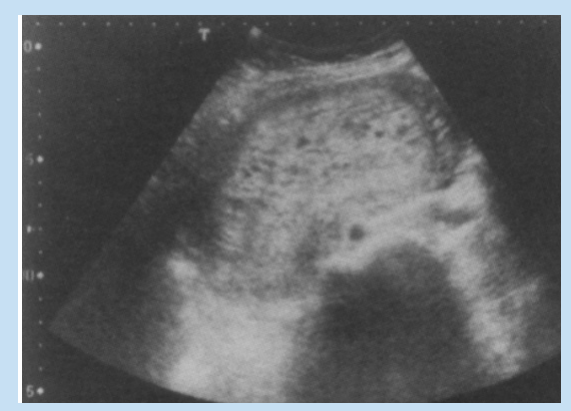

Fig. 1a. Transabsominal transverse scan showing a vesicular echogenic mass filling the endometrial cavity.

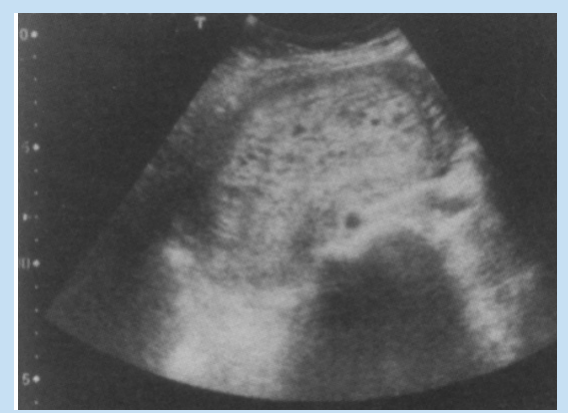

Fig. 1b. Transabdominal longitudinal scan.

abdominal hysterectomy and the diagnosis was subsequently confirmed on histological examination.

\section{Discussion}

Complete molar pregnancy is part of the spectrum of disorders characterised by abnormal proliferation of pregnancy-related trophoblasts. It is characterised by chromosomal DNA exclusively of paternal origin. It occurs when a normal haploid sperm fertilis- es an ovum with absent or inactive maternal chromosomes.

The aetiology is unknown, but several factors play a role. These include folic acid-deficient diet, age younger than 20 years or older than 40 years. The incidence among women older than 50 years is 1:2 pregnancies.

At pathology there is no fetal development and the placenta is entirely replaced by abnormal, hydropic chorionic villi with excessive trophoblastic proliferation.

It is characterised by excessive uterine size, as well as B-HCG levels in the 100 000s IU/l (normal pregnancy values are $\pm 60000 \mathrm{IU} / \mathrm{l})$, hyperemesis gravidarum, toxaemia, hyperthyroidism and respiratory failure. Vaginal bleeding exists in over $90 \%$ of cases. $^{2}$

\section{Sonographic features}

Sonographic features include: $(i)$ enlarged uterus containing echogenic tissue expanding into the endometrial cavity; (ii) uniformly distributed cystic spaces; (iii) no fetus; and (iv) bilateral greatly enlarged ovaries with multiple theca lutein cysts. ${ }^{2}$

Treatment depends on the patient's age. In patients over 40 years the treatment of choice is total abdominal hysterectomy. Patients younger than 40 years are treated with suction curettage. Both groups are followed up with serial B-HCG measurements and ultrasound.

\section{References}

1. Nel JT. Core Obstetrics and Gynaecology. Johannesburg: Heinemann, 1996: 599-606.

2. Rumack CM, Wilson SR, Charboneau JW. Diagnostic Ultrasound. 2nd ed. USA: Mosby, 1997: 1359-1362. 